\title{
Masuk Melayu Menegosiasikan Islam dan Kemelayuan di Malaysia
}

\author{
Steve G. Chr. Gaspersz \\ Fakultas Teologi Universitas Kristen Indonesia Maluku (UKIM) \\ E-mail:sgasperz@yahoo.com
}

\begin{abstract}
This paper elaborates the construction of religious identity (Islam) and ethnicity (Malay) through ideological concept 'Masuk Melayu' (lit. 'becoming Malay') in Malaysia. The intertwined religion and ethnicity bring about political notion and practice which combine both as an ideology of political culture in Malaysia. The ideology has been used as a parameter to manage political and societal life with the multicultural characteristic in Malaysia. It also demonstrates that the construction of religious identity and ethnicity in Malaysia, as well as other Southeast Asia countries, generally might not be separated from colonialism discourse occurred in the past. Colonialism had inherited socio-cultural and political systems by which, then, become the foundation of governmental bureaucracy activity and the establishment of a political culture of Southeast Asia societies until today. The postcolonial government in Malaysia, however, has been continuing such construction of identity by adding contextual political meaning and practice innovatively to maintain and sustain their political power. Masuk Melayu is an arena for negotiating political power by injecting religious identity of Islam as a powerful political axis in Malaysia.
\end{abstract}

Keywords: Melayu, postcolonial, ethnicity, Islamization

\begin{abstract}
Abstrak
Artikel ini mengelaborasi konstruksi identitas religius (Islam) dan etnisitas (Melayu) melalui konsep ideologis "Masuk Melayu" di Malaysia. Keberjalinan agama dan etnisitas membentuk paham dan praktik politik yang mengombinasikan keduanya menjadi suau ideologi politik kebudayaan di Malaysia. Ideologi tersebut telah digunakan sebagai parameter untuk mengelola kehidupan sosial dan politik dengan karakteristik multikultural di Malaysia. Artikel ini juga memperlihatkan bahwa konstruksi identitas religius dan etnisitas di Malaysia maupun negara-negara lain Asia Tenggara pada umumnya tidak bisa dipisahkan dari diskursus kolonialisme yang terjadi pada waktu lampau. Kolonialisme telah mewariskan sistem-sistem sosiobudaya dan politik yang kemudian melaluinya menjadi fondasi aktivitas birokrasi pemerintahan dan pembentukan budaya politik masyarakat Asia Tenggara hingga saat ini. Namun, pemerintahan pascakolonial di Malaysia terus melanjutkan konstruksi identitas semacam itu dengan menambahkan makna dan praktik politik yang kontekstual secara inovatif untuk mempertahankan dan melanjutkan kekuasaan politik mereka. "Masuk Melayu" adalah suatu arena untuk menegosiasikan kekuasaan politik dengan menginjeksi identitas religius Islam sebagai poros politik yang perkasa di Malaysia.
\end{abstract}

Kata Kunci: Masuk Melayu, pascakolonial, etnisitas, Islamisasi 


\section{Pendahuluan}

Asia Tenggara tidak hanya dianggap sebagai kawasan geopolitik yang terdiri dari bangsa-bangsa yang mempunyai pengalaman-pengalaman ekonomi dan politik bersama di bawah kolonialisme Barat. Kawasan ini juga meliputi berbagai spektrum kebudayaan dari masyarakat yang memiliki kesamaan karakteristik kebudayaan dan perbedaan-perbedaan yang disebabkan oleh konstruksi sosial selama kolonialisme. Mereka berbagi dimensidimensi kebudayaan seperti bahasa, mitos, kebiasaan, artefak, ritual, teknologi, kepentingan ekonomi dan rute-rute perdagangan, yang kemudian dibelah di bawah berbagai kategorisasi dan identifikasi kolonial yang menempatkan mereka sebagai kelompok-kelompok masyarakat yang terfragmentasi. Asia Tenggara pascakolonial mendapati dirinya sebagai masyarakat majemuk yang dalam banyak aspek menggambarkan segregasi berdasarkan keberbedaan dalam identitas-identitas sosiopolitik.

Di antara yang lainnya, Malaysia adalah salah satu negara yang penting di Asia Tenggara. Setelah kemerdekaannya pada tahun 1957 Malaysia telah berkembang sebagai salah satu negara pascakolonial modern di Asia Tenggara, bahkan di dunia, yang sejak awalnya memproklamasikan fondasi nasionalnya berdasarkan etnisitas (Melayu) dan agama (Islam). Keberjalinan identitasnya ini telah menempatkan Malaysia sebagai suatu negara dengan karakteristik etnoreligius dan tendensi politik yang kuat, bahkan jika dibandingkan dengan negara-negara di kawasan Timur Tengah.

Artikel ini memusatkan perhatian pada konsep "Masuk Melayu" yang menandai konstruksi kemelayuan di Malaysia sebagai fenomena unik dari kontestasi identitas etnis dan religius. Secara historis, "Melayu" sebenarnya mengacu kepada konteks prakolonial dinasti kesultanan di Kerajaan Melaka. Ketika sultan memeluk Islam sebagai agama kerajaan, langkah itu kemudian diikuti oleh rakyat untuk memperlihatkan kesetiaan mereka kepada kesultanan. Sejak saat itu, "Masuk Melayu" secara gradual diasosiasikan dengan "Masuk Islam" sebagai penanda identitas yang berkelindan di Jazirah Melayu.

Selama era kolonial, "Masuk Melayu" dikonstruksikan secara politis oleh penguasa kolonial untuk mengidentifikasi keberbedaan (otherness) antara kaum "[kulit] putih" dan "berwarna" (colored). Mereka menciptakan distingsi sosial semacam itu sebagai bagian dari hegemoni sosio-politik untuk menundukkan masyarakat pribumi berdasarkan pemahaman diri yang telah ada. Konsep "Masuk Melayu" selama kolonialisasi bangsabangsa Eropa mempunyai makna yang berbeda-beda tergantung pada kepentingan politik penguasa kolonial saat itu. Anthony Reid mencatat bahwa "in the western Archipelago Masuk Melayu meant to become a Muslim, but in parts of eastern Indonesia the phrase meant becoming Christian" (Reid, 2001).

Berkenaan dengan isu "Masuk Melayu" maka artikel ini berupaya untuk mengelaborasi pertautan antara agama dan etnisitas dalam mengonstruksi identitas kemelayuan di Malaysia. Elaborasi ini didasarkan pada pertanyaan: Bagaimana hubungan antara Islam dan negara di Malaysia? Seberapa jauh Islam memberi dampak pada urusanurusan publik dan kebijakan-kebijakan luar negeri di Malaysia?

\section{Metode Penelitian}

Penelitian ini adalah penelitian literatur agar memperolah konsep yang kuat tentang Asal usul melayu, sejarah dan etnisitas sehingga tulisan ini dapat mengungkap hubungan pengaruh Islam dengan situasi di negeri Malaysia. 


\section{Hasil Dan Pembahasan}

\section{A. Asal-usul "Melayu": Sejarah dan Etnisitas}

Konsep "Melayu" mempunyai beraneka makna historis dan kompleksitas perkembangan budayanya terutama berkaitan dengan konteks nation-building negaranegara pascakolonial Asia Tenggara, terutama Indonesia dan Malaysia. "Melayu" adalah suatu identitas yang diimajinasikan yang melaluinya suatu negara, sejak periode kolonialisme dan kemerdekaan, merujuk pada signifikansi nasionalisme dalam masyarakat multietnis Malaysia.

Untuk menjelaskan model nasionalisme di Asia Tenggara, Reid menyatakan bahwa perkembangan nasionalisme di kawasan ini secara esensial terbentuk dalam dikotomi antara "model teritorial" dan "model etnis". Yang pertama adalah negara dengan batasbatas geografis yang secara kultural menciptakan satu bangsa yang koheren; sedangkan yang kedua berdasarkan atas suatu kelompok etnis dengan batas-batas yang kabur namun berupaya memperoleh batas-batas dan status politik yang layak (Reid, 2001).

Sebagai suatu identitas yang diimajinasikan, "Melayu" memiliki dimensi mitis. Itu menjadi mitos yang kemudian dikonstruksikan sebagai suatu narasi sosial untuk membedakan kelompok-dalam (ingroup) dan kelompok-luar (outgroup); atau sebagai referensi simbolis untuk menegosiasikan perbedaan-perbedaan demi mencapai ikatan kultural dengan nilai-nilai yang dihidupi bersama dalam konteks tertentu. Craig R. Prentiss menyatakan (Prentiss, 2003):

" a narrative that only claims truth for itself but is also seen by a community as credible and authoritative... When a community sees a story as authoritative, the story is understood as setting a paradigm for human behavior. In other words, human beings point to the story to authorize (give authority to) their preferences, to justify or re-create their social patterns, or to guide their decision makings".

Dengan menceritakan kisah-kisah otoritatif semacam itu, kelompok-kelompok sosial tertentu secara terus-menerus mengonstruksi identifikasi diri mereka sendiri serta menjustifikasi kuasa dan peran khusus mereka berkaitan dengan relasi-relasi kuasa dengan kelompok-kelompok yang mereka klaim sebagai liyan. "Mitos" tersebut mendorong masyarakat untuk mengimajinasikan kelompok-dalam mereka sebagai unik dan/atau superior dibandingkan berbagai kelompok-luar. Bagi Prentiss, ras dan etnisitas adalah dua konsep sosiologis yang mendeterminasi identifikasi di kalangan kelompok-kelompok yang berbeda berdasarkan mitos tersebut. Ras adalah suatu pengelompokan sosial atau paguyuban (peoplehood) yang ditandai oleh hal-hal yang diterima sebagai warisan biologis; sedangkan etnisitas adalah suatu pengelompokkan sosial atau bentuk kemasyarakatan yang ditandai oleh hal-hal yang diterima sebagai warisan kultural (Prentiss, 2003).

Mitos atau kisah-kisah otoritatif seperti apa yang digunakan sebagai kejadian identitas "Melayu"? Ada banyak konsepsi yang menandai cara rumit untuk menentukannya dan tidak ada perspektif tunggal. Dengan menggunakan observasi linguistik dan analisis migrasi, Leonard Andaya menelusuri prasasti-prasasti dan dokumen-dokumen klasik untuk mengidentifikasi "Melayu". Dia menegaskan adanya suatu bahasa proto-Melayu dari sekitar 2000 tahun lampau. Para penutur bahasa itu tersebar dari sebelah barat Borneo 
hingga ke sebelah tenggara Sumatera dan Jazirah Melayu. Bukti pertama dari bahasa tulis Melayu telah ditemukan pada prasasti-prasasti abad ke-7 di Palembang, dan nama "Melayu" pertama kali disebutkan dalam suatu dokumen Cina abad ke-7 yang menunjuk pada wilayah Palembang dan Jambi (Andaya, 2001).

\section{B. Mendefinisikan Melayu}

Sejak abad-abad ke-7 hingga ke-14, peradaban Sriwijaya yang berbasis di Sumatera telah menguasai sebagian besar kawasan Melayu-Indonesia, mengimpor sistem-sistem hukum dan politiknya dari prinsip-prinsip animis dan Hindu-Budha yang datang dari India. Islam tiba di Malaya melalui pedagang-pedagang Arab dan India yang kerap menempuh rute-rute perdagangan laut Asia Tenggara sejak abad ke-8. Situasi ini secara gradual menggiring pada konversi sebagian besar dunia Melayu-Indonesia menjadi Islam dan meruntuhkan imperium Sriwijaya menjadi banyak kesultanan kecil, yang paling menonjol dari situ adalah pelabuhan dagang Melaka yang dijuluki "Venisia dari Timur" abad ke-15 (Lee, 2008).

Sejak abad-abad ke-14 hingga ke-15 para elite penguasa (para sultan dan dinasti kerajaan) mulai memeluk Islam, yang kemudian memasukkan prinsip-prinsip hukum dan pemerintahan Islami (Means, 1978). Carolina Lopez menegaskan (Lopez, 2001),

"The royal court system inherited from the pre-Malaccan period, overlaid with Islamic understanding of divine law and governance, form the basis for both the system of governance and the larger worldview prevalent in the Malay World... It might be said that Islam was 'grafted' onto the existing structure and, over time, took increasingly deeper root in the worldview, values and identity construction of the Malaccan sultanate"

Islam juga kemudian dianut oleh masyarakat awam dan para pedagang karena keuntungan yang diperoleh dengan mengidentifikasi diri dengan agama penguasa. Ini merupakan salah satu contoh pertama yang tercatat mengenai pluralisme etnis dan religius di Malaysia, sebagaimana Islam tidak dipaksakan kepada para penduduk dan pedagang yang multi-religius di Kerajaan Melaka (Yeoh, 2006).

Penerimaan Islam oleh para penguasa Melayu telah membawa dimensi-dimensi baru bagi hubungan antara warga negara dan penguasa. Sebelum agama Islam menjadi sangat berpengaruh di Jazirah Melayu, status "Melayu" dipasang pada prinsip-prinsip garis keturunan dan dibatasi hanya pada keturunan raja. Hubungan politik secara bertahap menjadi suatu ikatan "etnis" semenjak kesultanan menganut Islam. Sebagai suatu agama dengan seluruh domain ritual-kultural, Islam mendorong kepenuhan-diri dari setiap jamaah berkaitan dengan ketaatan religius (Nagata, 1984). Hal ini menumbuhkan solidaritas horizontal di kalangan rakyat yang patuh kepada penguasa.

Perluasan identitas Melayu melalui Islam juga mencakup penggunaan bahasa. Bahasa Melayu dipropagandakan melalui penyebaran Islam, yang tidak hanya memasukkan katakata serapan dari bahasa Sansekerta sebelumnya tetapi juga konsep-konsep teologis Islami dari Arab. Selama periode antara abad-abad ke-16 dan ke-20 konsepsi kemelayuan terkristalisasi dalam seluruh kesultanan di Jazirah Melayu dengan tumbuhnya kesadaraan akan kesamaan bahasa, kebudayaan dan iman (Nagata, 1984).

Agama dan kebudayaan telah menyatu pada derajat bahwa konversi orang-luar menjadi Islam akan membuatnya secara otomatis layak menyandang status "Melayu" 
(masuk Islam, masuk Melayu). Hanya ada sedikit Muslim non-Melayu, sebagian besar adalah orang India, Arab atau kelompok-kelompok dari kepulauan Indonesia yang diasimilasikan ke dalam komunitas Melayu melalui proses saling kawin-mawin (Mohd, 2010). Juga ada bukti mengenai ikatan-ikatan rasial yang longgar melalui saling kawinmawin antara orang-orang Cina dan Melayu, yang dikenal sebagai Baba atau komunitas Cina Selat (Straits Chinese) di Penang dan Melaka.

Sebagai satu keseluruhan, terbentuklah perdamaian dalam relasi-relasi antar-etnis seperti yang tampak melalui contoh-contoh para elite tradisional Melayu dan Cina yang terlibat dalam kerja sama saling menguntungkan. Aspek penting lain juga adalah bahwa identitas Melayu tidak punya privilese politik atau ekonomi yang luar biasa, suatu isu yang kemudian menjadi salah satu sumber ketegangan antar-etnis.

\section{Masuk Melayu: Isu-isu Agama dan Negara}

Dengan kedatangan kolonialisme dan imigrasi, batas-batas identitas etnis perlahanlahan makin menguat dan mengeras. Selama penguasaan Inggris, kelompok-kelompok etnis di Malaya ditandai sebagai orang Cina, orang India dan orang Melayu melalui kategori-kategori sensus, dengan mengabaikan realitas rumit saling-kawin atau kelompokkelompok sub-etnis (Lopez, 2001). Aspek umum di kalangan kelompok-kelompok Melayu yang berbeda-beda itu adalah mereka mempunyai orientasi bersama terhadap Islam. Akan tetapi, penguasa Inggris mengembangkan ideologi mengenai perbedaan-perbedaan "rasial" yang inheren yang secara permanen mengubah bentuk pluralisme etnis dan religius di Malaysia (Hirschman, 1986).

Batas-batas demarkasi artifisial ikatan-ikatan etnis dan kebijakan pecah-belah Inggris atas berbagai kelompok etnis telah mempertajam ketegangan antar-etnis. Status relasirelasi antar-etnis ditransformasikan sebagaimana Inggris menerapkan teori rasial Eropa dan mereproduksi tatanan sosial dan ekonomi yang dibentuk oleh ras. Penguasa Inggris telah memisahkan klas penguasa, para sultan, dari hak-hak feodal mereka berhadapan dengan klas rakyat, dengan hanya membolehkan mereka untuk mempertahankan kedaulatan atas tradisi-tradisi Melayu yang meliputi adat, bahasa dan Islam (Shamsul, 1997).

Semua Melayu adalah Muslim dan berbicara Melayu yang, meskipun memiliki perbedaan dialek dalam tuturan, merupakan bahasa umum dalam standar bentuk tulisnya. Pada sisi lain, orang Cina dan orang India secara internal terbagi berdasarkan garis-garis agama, bahasa dan kebudayaan. Komunitas-komunitas Melayu dan non-Melayu mendapat pengaruh yang berbeda dari ekonomi modern. Orang Melayu kebanyakan adalah komunitas pedesaan yang bekerja sebagai petani dan nelayan; klas pekerja lebih didominasi oleh non-Melayu. Sebagai hasil kebijakan Inggris berkaitan dengan komunitas Melayu sebagai penguasa yang sah di negara ini, jabatan-jabatan tertinggi di birokrasi terutama merupakan privilese Melayu, sementara kelompok-kelompok non-Melayu mendominasi bidang-bidang perdagangan, profesional dan klas pekerja (Crouch, 1996).

Inggris menempatkan klas pemerintahan berpendidikan Inggris yang direkruit dari aristokrasi Melayu. Anggota-anggota dari klas ini menduduki eselon-eselon tertinggi dalam birokrasi setelah kemerdekaan Malaysia. Melayu dan non-Melayu direkruit untuk jabatan-jabatan perwira di kepolisian dan angkatan bersenjata tetapi posisi-posisi tertinggi umumnya didominasi oleh Melayu. Sembari mengendalikan birokrasi, kepolisian dan 
angkatan bersenjata, para elite Melayu juga melebarkan sayap politik dengan mendirikan United Malays National Organisation (UMNO). Anggota-anggota dari para elite pemerintahan berpendidikan Inggris yang bekerja bagi pemerintah kolonial sebagian besar adalah generasi pertama para pemimpin UMNO.

UMNO dibentuk tahun 1946 untuk merespons rencana Inggris menciptakan Perserikatan Melayu keluar dari sembilan negara Melayu dan dua koloni di Jazirah tersebut. Mereka mempertimbangkan bahwa rencana tersebut akan mengancam status khusus mereka sebagai komunitas pribumi dan pada gilirannya memberikan hak-hak kewarganegaraan yang sama dengan kaum Melayu kepada kelompok-kelompok nonMelayu. Namun, komposisi sosial Malaysia sebagai suatu masyarakat multi-etnis dengan segera membuat para pemimpin UMNO sadar bahwa stabilitas politik hanya dapat dipertahankan melalui kerja sama dengan para pemimpin non-Melayu yang moderat. Tahun 1952, UMNO akhirnya bergabung dengan Asosiasi Cina Melayu (Malayan Chinese Association - MCA) dalam suatu aliansi menentang partai multirasial yang dipimpin oleh orang Melayu.

Harold Crouch menyatakan bahwa sistem politik Malaysia memiliki beberapa karakteristik consociationalism, yaitu stabilitas politik dalam masyarakat majemuk dapat dicapai melalui integrasi pada tingkat elite meskipun komunitas-komunitas yang direpresentasikan oleh para elite tersebut tetap berseteru (Crouch, 1996). Selama tahun 1969, fondasi-fondasi konsosiasional dari sistem tersebut makin goyah karena pembangunan sosial dan ekonomi pada periode pasca-kemerdekaan.

Konsep kemelayuan dalam Malaysia kontemporer menjadi sangat berpengaruh ketika diartikulasikan oleh Mahathir Mohammad dalam bukunya The Malay Dilemma (1970). Ia menemukan akar dilema Melayu dalam arti kaum Melayu makin tersingkir di tanahnya sendiri. Pada era pra-Inggris, orang-orang Cina, India, Arab, dan para pedagang lain telah datang ke Jazirah Melayu dimana masyarakatnya telah berbicara dengan bahasa Melayu, mengadopsi kebiasaan-kebiasaan Melayu, dan mengawini orang-orang Melayu. Sebagai hasilnya, mereka sepenuhnya terserap ke dalam komunitas Melayu. Mahathir gelisah dengan gelombang imigrasi yang masif selama periode kolonial yang telah menciptakan berbagai komunitas tersendiri yang terpisah-pisah dan hanya memiliki sedikit kecenderungan untuk menerima tradisi-tradisi yang telah hidup dari apa yang disebutnya sebagai definitive people.

Melayu umumnya merujuk pada Malaysia, khususnya Jazirah Malaysia, sebagai "Tanah Melayu". Orang Melayu dan komunitas lokal lainnya digambarkan sebagai "bumiputera" yang secara kultural kontras dengan orang-orang Cina dan India yang sering disebut "orang dagang". Akan tetapi, dalam praktiknya, tidak ada pilihan selain menerima realitas keberadaan sejumlah besar orang non-Melayu. Tahun 1957, para pemimpin UMNO, MCA dan MIC mencapai kesepakatan bahwa orang Melayu harus mendominasi pemerintahan, sementara orang non-Melayu diberi status kewarganegaraan dan dijamin bahwa posisi mereka dalam bidang ekonomi tidak akan diganggu. Juga disetujui bahwa simbol-simbol negara baru ini adalah Melayu: Yang di Pertuan Agong sebagai kepala negara, Islam sebagai agama negara, dan Melayu sebagai bahasa nasional.

Untuk mengafirmasi apa yang disebut Melayu sebagai identitas nasional, pemerintah mensponsori kongres kebudayaan nasional tahun 1971 yang mengadopsi tiga prinsip dalam mendefinisikan kebudayaan nasional: [1] kebudayaan nasional harus didasarkan pada kebudayaan pribumi di kawasan ini; [2] unsur-unsur yang cocok dari berbagai 
kebudayaan lain dapat diterima sebagai bagian dari kebudayaan nasional; [3] Islam adalah komponen penting dalam memperkuat kebudayaan nasional. Kebudayaan Melayu jelas diperlakukan seolah-olah itu sinonim dengan kebudayaan Malaysia. Keputusan kongres itu kemudian diadopsi oleh pemerintah sebagai dasar bagi kebijakan kebudayaannya sendiri meskipun sebagian besar kelompok non-Melayu tidak menerimanya.

Tendensi politik di Malaysia sangat jelas diarahkan oleh suatu pola etnoreligius. "Masuk Melayu" berarti menganut Islam dan sebaliknya. Seorang Melayu yang menolak Islam tidak lagi dianggap sebagai Melayu. Konstitusi Federal mendefinisikan "orang Melayu" sebagai "a person who professes the religion of Islam, habitually speaks the Malay language [and] conforms to Malay custom" (Federal Constitution, article 160[2]). Namun, tidak semua bumiputera adalah Muslim. Sebagai contoh, orang-orang asli jazirah dan banyak komunitas lokal di sebelah timur Malaysia, seperti Kadazan di Sabah dan Iban di Sarawak menolak Islamisasi dan - dalam beberapa kasus - menganut Kekristenan.

Program Islamisasi dilakukan oleh pemerintah (dipimpin oleh Mahathir sebagai Perdana Menteri) sekitar era 1980-an. Mahathir mendeklarasikan bahwa "UMNO's struggle has not ended. Today we face the biggest struggle - the struggle to change the attitude of the Malays in line with the requirements of Islam in this modern age... UMNO's task now is to enhance the Islamic practices and ensure that the Malay community truly adheres to Islamic teachings." Beberapa langkah praktis telah diambil untuk tujuan itu, seperti melarang impor daging sapi non-halal, melarang Muslim memasuki kasino Genting Highlands, meresmikan Bank Islami dan Universitas Islami Internasional.

Ide Mahathir ini berdampak sangat besar bagi kesadaran politik berbasis privilese kemelayuan sebagai kelompok pribumi yang memiliki hak-hak sosio-budaya atas tanah tersebut. Sejarah dan atmosfer politik Malaysia sejak saat itu memperlihatkan suatu pergolakan sosial untuk menegosiasikan berbagai perbedaan identitas dan kepentingankepentingan sosio-politis. Shamsul menyatakan bahwa "if previously Islam was mainly expressed in symbolic terms, especially in relation to the institution of the royalty and popular Malay culture, the government's effort drew Islam into the heart of all economic and noneconomic life" (Shamsul, 1997).

Penguatan identifikasi Melayu dengan Islam bersamaan dengan implementasi New Economic Policy (Kebijakan Ekonomi Baru - NEP). Menurut Dicky Sofjan, NEP telah memberikan ketentuan-ketentuan bagi diskriminasi positif terhadap kaum bumiputera dan membangun suatu klas kapitalis Melayu (Sofjan, 2007). Kaum Melayu pedesaan telah berpindah ke kota-kota, termasuk banyak mahasiswa di lembaga-lembaga pendidikan tersier (klas tiga). Kondisi ini telah memunculkan suatu tipe baru Melayu yang memasuki dunia perkotaan (urban) selama masa polarisasi dan kecurigaan rasial yang terjadi pasca kerusuhan rasial tahun 1969. Selain dorongan untuk meraup keuntungan-keuntungan ekonomi, kaum Melayu dimobilisasi untuk mendukung bahasa Melayu, ketaatan kepada adat Melayu, dan Islam. Kebangkitan kesadaran Islami, dengan demikian, adalah bagian dari suatu penguatan umum kesadaran komunal. Identitas keagamaan umumnya memperkuat etnisitas, meskipun ada Muslim non-Melayu. Ini juga berdampak pada kembalinya paham

"Ketuanan Melayu: Ketuanan Melayu connotes a system that bestow special rights and privileges, as enshrined in Article 153 of the Federal Constitutions, to the largest 
indigenous class and gives surety to the preponderance of the Bangsa Melayu or Malay race as tuan (masters) (Sofjan, 2007)."

NEP diikuti oleh berbagai kebijakan kebudayaan yang menyimbolkan bangkitnya Melayu (Crouch, 1996). Kebudayaan Melayu juga diperkuat melalui upacara-upacara resmi dan program-program televisi, serta Islam sepenuhnya diidentifikasikan dengan negara. Dalam praktiknya, kelompok non-Melayu terus berbicara bahasa-bahasa Cina dan Tamil, serta banyak sekali lingkup bagi ekspresi kebudayaan non-Melayu dan kebebasan beragama masih dihormati. Namun, banyak kaum non-Melayu merasa teralienasi dari negara yang mereka lihat makin teridentifikasi dengan nilai-nilai Melayu.

\section{Kesimpulan}

Pemahaman mengenai dinamika sosio-politik di Malaysia mesti dilihat secara holistik dari berbagai perspektif, yaitu sejarah (tahapan-tahapan kolonialisme dan pascakolonial), transformasi kebudayaan, dan pembangunan ekonomi. Sebagai salah satu negara-bangsa pascakolonial di Asia Tenggara, masyarakat dan pemerintah Malaysia mewarisi berlapislapis pengaruh dari kolonialisasi Inggris dan pembangunan ekonomi global sejak kemerdekaannya tahun 1957.

Kompleksitas komposisi sosialnya yang multietnis telah mendorong konstruksi sistem politik berdasarkan suatu tipe ideal bahwa Melayu harus dipromosikan sebagai patron tunggal identitas negara. Tipe ideal semacam itu kemudian direalisasikan dalam komposisi M-c-i-o (Malay-chinese-indian-others) yang dilihat oleh negara sebagai kebijakan strategis untuk mempertahankan stabilitas nasional di Malaysia. Pada kenyataannya, agama digunakan oleh negara sebagai agensi politik untuk memberi legitimasi bagi konstitusi atau regulasi negara berkaitan dengan ketegangan-ketegangan sosial akibat sentimensentimen etnis.

Secara efektif Islam menjadi suatu penanda politik oleh negara untuk mengelola diversitas sosial di Malaysia. Tidak hanya berdasarkan ajaran-ajaran dasarnya secara teologis tetapi lebih jauh dengan melekatkan identitas Melayu sebagai dimensi integral dari Islam. Melayu dan Islam adalah satu identitas - "Masuk Melayu" berarti "masuk Islam" dan, demikian pula sebaliknya, "masuk Islam" dianggap menjadi "orang Melayu". Dengan demikian, Melayu dan Islam tidak dapat dipisahkan sama sekali. Negara atau elite penguasa membangkitkan kembali mitos superioritas Melayu sebagai narasi utama nasional untuk membangun fondasi negara-bangsa ini.

Interpenetrasi dan/atau interaksi antara agama dan negara telah menjadi karakteristik sosio-politik utama di Malaysia dan negara-negara lain di Asia Tenggara. Artinya, untuk memahami sistem politik di Malaysia, orang tidak dapat menghindari atau mengabaikan signifikansi agama. Tidak seperti negara-negara modern Barat yang membuat pemisahan tegas antara agama dan negara, sistem politik dan ideologi negara di Malaysia dengan sengaja mempertimbangkan keduanya sebagai unsur-unsur paling potensial untuk mempertahankan stabilitas sosial.

Selain itu, perpaduan agama-negara dalam suatu sistem politik juga memperlihatkan kemampuan untuk mengadaptasi warisan kolonial menjadi suatu sistem demokrasi kontemporer, serta keterlibatan visioner dalam pembangunan ekonomi global tanpa kehilangan identitas nasional. Islam menawarkan suatu sistem ekonomi alternatif melawan kapitalisme sebagaimana yang diintroduksi oleh kolonialisme pada masa lalu, dan kini neo-kolonialisme; sedangkan Melayu telah ditegaskan sebagai oposisi terhadap klas 
"Putih". Hibriditas semacam ini sebenarnya digunakan sebagai resistensi terhadap hegemoni Barat (secara kultural maupun ekonomis) seperti yang dapat ditemukan dalam sebagian besar negara-negara pascakolonial di Asia Tenggara sekarang. Secara teoretik, pembangunan sistem politik di Asia Tenggara, terutama Malaysia, menegaskan gambaran bahwa konsep negara modern di kawasan ini telah bergerak ke arah yang berbeda dengan negara-negara Barat.

Saling pengaruh agama dan negara dalam sistem politik Malaysia memberi gambaran bahwa sebagai hasil kolonialisasi dan kemajuan untuk terlibat dalam konteks ekonomi global, bangsa ini perlu memodifikasi paradigma baru dalam ruang politik. Dengan melakukan itu, negara dapat bergerak lebih leluasa dengan menggunakan seluruh sumber daya politik yang tersedia, termasuk agama dan etnisitas.

\section{Daftar Pustaka}

Andaya, L. (2001). The Search for the "Origins" of Melayu. Journal of Southeast Asian Studies, 32 (3).

Crouch, H. (1996). Government and Society in Malaysia. Ithaca: Cornell University Press.

Hirschman, C. (1986). The Making of Race in Colonial Malaya: Political Economy and Racial Ideology. Sociological Forum, 1.

Lee, L.-N. (2008). Who Represents the Muslims? Contesting Identities in Malaysia and France. Middletown: Wesleyan University.

Lopez, C. (2001). The British Presence in the Malay World: A Meeting of Civilizational Traditions. Sari, 19.

Means, G. P. (1978). Public Policy Toward Religion in Malaysia. Pacific Affairs, 51.

Mohd, S. (2010). Ethnic Identity Dilemma - A Case Study of the Indian Muslims in Penang, Malaysia. International Review of Business Research Papers, 6.

Nagata, J. (1984). The Reflowering of Malaysian Islam: Modern Religious Radicals and Their Roots. Toronto: University of British Columbia Press.

Prentiss, C. R. (Ed.). (2003). Religion and the Creation of Race and Ethnicity: An Introduction. New York: New York University Press.

Reid, A. (2001). Understanding Melayu (Malay) as a Source of Diverse Modern Identities. Journal of Southeast Asian Studies, 32 (3).

Shamsul, A. B. (1997). Identity Construction, Nation Formation, and Islamic Revivalism in Malaysia. In R. Hefner \& P. Horvatich (Eds.), Islam in an Era of Nation-States: Politics and Religious Renewal in Muslim Southeast Asia. Honolulu: University of Hawaii Press.

Sofjan, D. (2007). The Malaysian Dilemma: Race, Religion and the Quest for National Unity.

Yeoh, C. R. (2006). Malaysia, Truly Asia? Religious Pluralism in Malaysia. The Pluralism Project. Cambridge: Harvard University Press.

\section{Acknowledge}

* Dr. Steve G. Chr. Gaspersz, M.A. adalah staf pengajar pada Fakultas Teologi Universitas

Kristen Indonesia Maluku (UKIM), Ambon. Meraih gelar Master of Arts dari Vrije Universiteit, Amsterdam dan gelar Doktor dari Indonesian Consorsium for Religious Studies (ICRS), Sekolah Pascasarjana Universitas Gadjah Mada (UGM). 